\title{
The analysis of "more electric engine" technology to improve the environmental performance of aircraft jet engine
}

\author{
Maciej Henzel ${ }^{1,{ }^{*}, K}$ Kzysztof Falkowski ${ }^{1}$, and Aleksander Olejnik ${ }^{1}$ \\ ${ }^{1}$ Military University of Technology, Faculty of Mechatronics and Aerospace, \\ gen. Witolda Urbanowicza 2, 00-908 Warsaw, Poland
}

\begin{abstract}
In aviation, there is now a dynamic development of aircraft equipment related to the implementation of "more electric aircraft" technology. This concept offers the ability to improve the use of on-board systems, e.g. environmental operating conditions of aircraft jet engine. This technology is named "more electric engine". It allows the use of magnetic levitation technology at engine turbine shaft bearing. The development of this technology relates to the dynamic change of electronic power systems for civilian transport aircraft, the use of adaptive control methods and new materials in aviation technology. All technologies are improved the environmental operating conditions of the on-board system, e.g. operational flexibility, technological potential growth. [1] In the paper will be presented the TS-21 aircraft jet engine. This engine is modernized in the Jet Engine Laboratory of the Military University of Technology. The paper is presented a digital engine control system, the operating parameters acquisition system and magnetic bearing system. It is described the concept of active magnetic suspension of the turbine engine shaft support. The magnetic suspension technology allows eliminate mechanical bearing arrangements with an oil installation, friction forces and classical, mechanical bearings. The paper contains the simulation and experimental results of a modernized jet engine TS-21.
\end{abstract}

\section{Introduction}

In the last years, in aviation there is developed new trend in aircraft equipment. This concept is called "More Electric Aircraft" (MEA) technology. It is based on the use of electric equipment, instead of pneumatic and hydraulic systems. The expansion of electrical machines, power systems and other electric devices are caused increase of demand for onboard electric energy. Thanks to this technology, new aircraft are produced less noise, pollution. This idea influences increase of maintenance susceptibility, ensure systems flexibility during modification. It reduces operation costs and system weight, too. More Electric Aircraft concept is used in passenger aircrafts Boeing B787, Airbus A380. There are

* Corresponding author: maciej.henzel@ wat.edu.pl 
applied e.g. environmental control systems, aircraft engines, electrical power and actuation systems. [1,2]

Jet engine is the main aircraft element produced in MEA technology. It works in hard and changeable conditions, e.g. high and low temperature, low pressure, high and changeable loading, high rotational speed, high lateral and longitudinal overloads. So, jet engine roll bearings are worked in very hard conditions, too. New concept of engine bearing system is based on magnetic suspension phenomenon. It eliminates mechanical contacts between stator and rotor, and removes negative operating effects such as friction forces, heat and wear, lubrication, heat dissipation, noise, etc.

The active magnetic bearing system (AMB) is implemented in some commercial engines. These bearings are perfectly suitable to support fan in "hot" engine section. Active magnetic bearings are devices, which using attraction forces to provide stable shaft engine levitation at work point. New system can work properly in rugged conditions. In aircraft engine domain, the new concept is named "all electric engine". In laboratory of the Military University of Technology, this idea is tested on the TS-21 jet engine. This engine is presented in the Figure 1 [4].

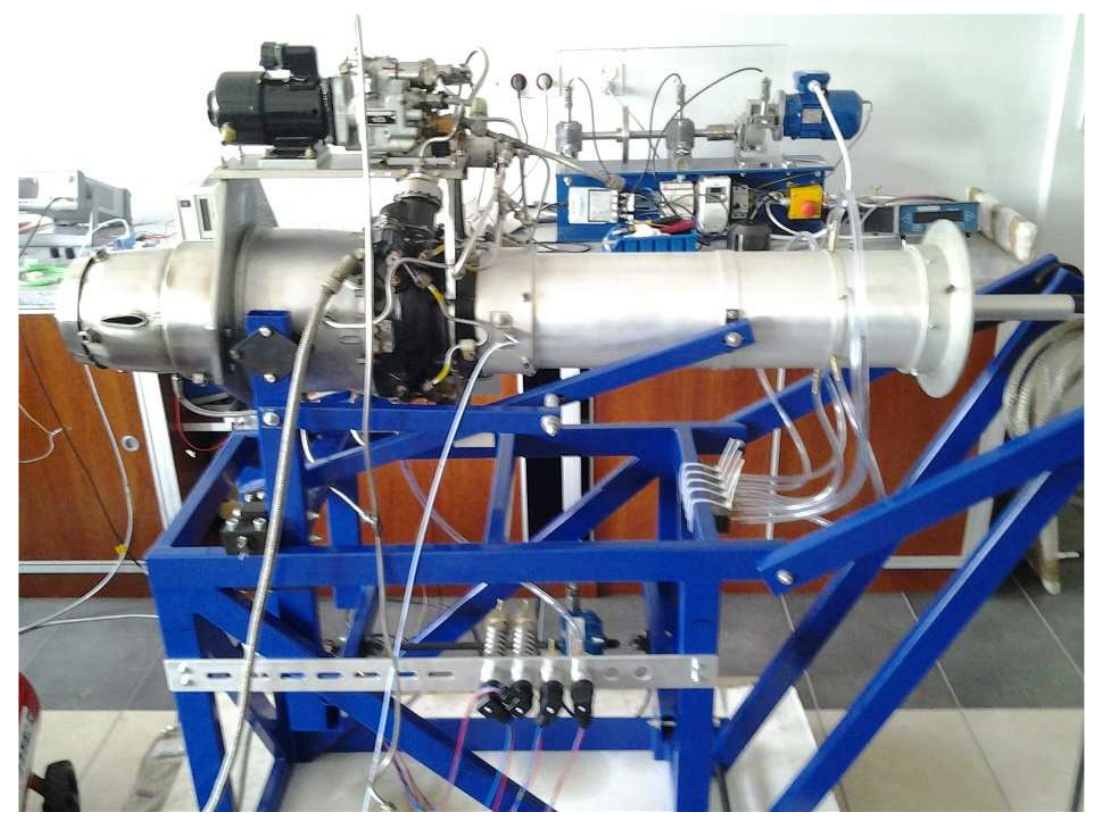

Fig. 1. The TS-21 jet engine on the lab stand

\section{New concept of jet engine shaft bearing}

The main elements of classic jet engine are rotor fan, low- and high- pressure compressors and turbines, two or one drive shafts, combustion chamber and bearings. The turbine is a drive source for all other components. Loads acting on these elements are created by the generation of thrust or power. Rotary systems are also loaded by centrifugal forces. These forces are changed in wide range, and they can be disturbed by residual unbalance influences. Moreover, compressive and stretching loads are affected engine rotary systems depending on thrust-support bearing location.

In classical engine constructions, roll bearings are worked in high rotor speed (over 40000 [rpm]), high longitudinal forces, high temperature (over $1200\left[{ }^{\circ} \mathrm{C}\right]$ ) and difficult lubrication conditions. Axial and radial forces are growth during engine acceleration, hard 
landings and during curvilinear aircraft motion. These bearings support turbine rotors and compressor. So, they are exposed to a continuous heat flow from the heated rotors. For that reason, they have to be cooling by oil system (Figure 2a). The described conditions eliminate the use of sliding bearings. But they indicate the advantageous features of the roll bearing, that have the small friction resistance. [4,5]
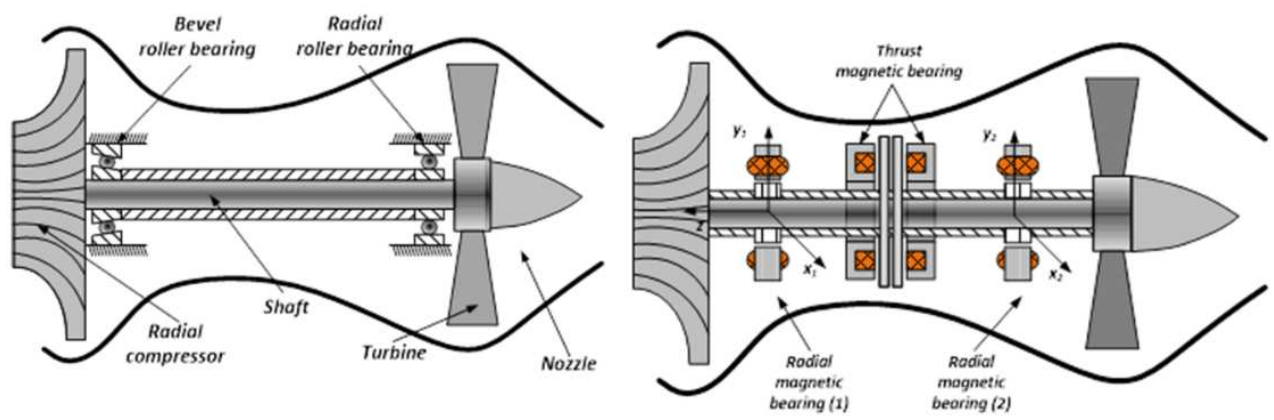

Fig. 2. Diagram of jet engine construction: a) classic construction, b) construction with magnetic suspension system[4]

New bearing concept bases on the use of active magnetic bearings for shaft jet engine (Figure 2b). These bearings consist of electro-mechanical actuator with stator and rotor. New construction of bearing system eliminates friction forces between co-operating kinematic pairs and makes possible to monitoring and diagnosing aircraft engine. Figure $2 b$ is shown the aircraft engine structure with magnetic bearings. Two radial magnetic bearings generate radial forces in two perpendicular radial axes. The first magnetic bearing (1) is controlled in two radial axis $x_{1}$ and $y_{1}$. And the second radial magnetic bearing (2) is controlled in radial axis $x_{2}$ and $y_{2}$. The axial position in the $z$-axis is controlled by a thrust magnetic bearing. $[2,3,6]$

\section{Finite element method analysis of the radial active magnetic bearings}

The further analyses described the radial magnetic bearings of the TS -21 aircraft jet engine. These bearings are placed on the left and right plane of the shaft turbine. The magnetic bearing construction is modelled in COMSOL Multiphysics software based on the finite element method analysis. This analysis is enabled the phenomena in proposed solution. There are modelled the geometric dimensions, mass and inertia parameters of the engine. Magnetic bearings are designed for a maximum load about $100 \mathrm{~N}$. The tests allowed to determine the magnetic circuits parameters and limits. The analysis are made possible to optimize the bearing weight and geometrical parameters. The established parameters of the magnetic bearing are described in the Table 1 .

The results of FEM analysis of passive electrodynamic bearing are presented in Figure 3 and Figure 4. There are shown the distributions of magnetic fields and the values of magnetic forces in the magnetic bearing. There are presented the magnetic induction distributions, the induced eddy currents, and the stiffness and damping parameters of the bearing. Stiffness parameter is estimated by the determination of the relationship between the magnetic force and the position of the shaft in the air gap. However, the damping parameter is estimated as the relationship between the magnetic force and the velocity of the shaft. 
Table 1. Vehicles dimensions

\begin{tabular}{|c|c|c|}
\hline Parameter & Value & Unit \\
\hline Maximum force & 100 & $\mathrm{~N}$ \\
\hline Saturation magnetic induction & 1,6 & $\mathrm{~T}$ \\
\hline Rotor diameter & 25 & $\mathrm{~mm}$ \\
\hline Air-gap & 0,3 & $\mathrm{~mm}$ \\
\hline Maximum current & 10 & $\mathrm{~A}$ \\
\hline Current density & 8 & $\mathrm{~A} / \mathrm{mm}^{2}$ \\
\hline
\end{tabular}

a)

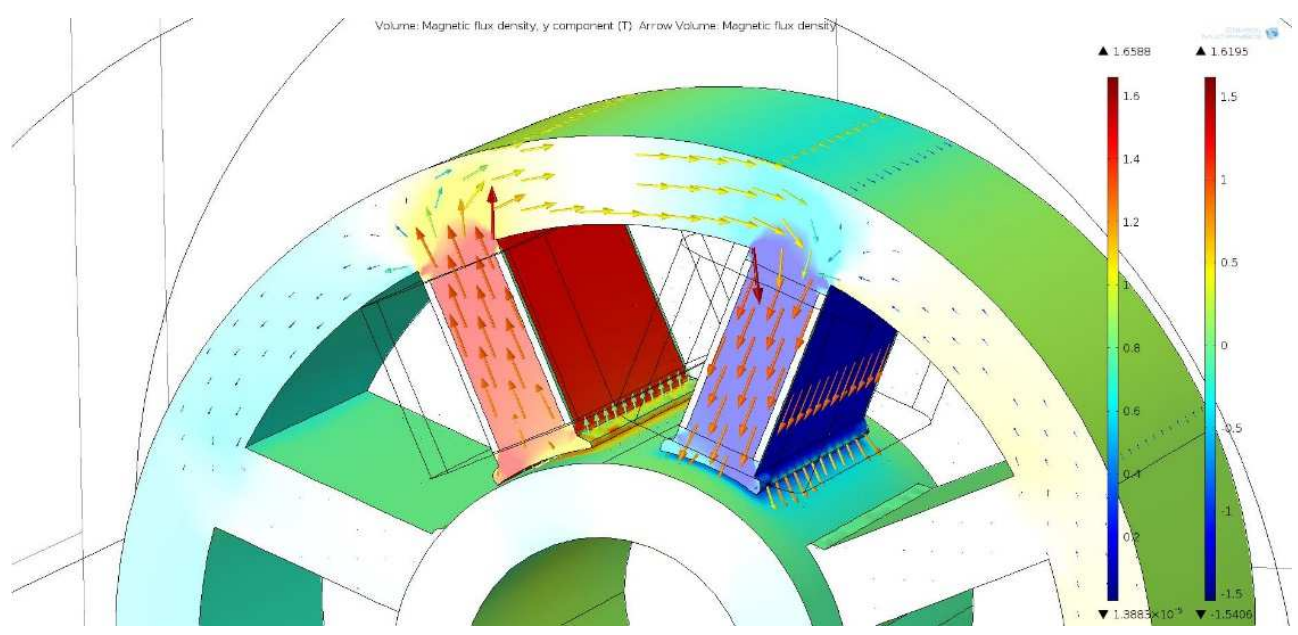

b)

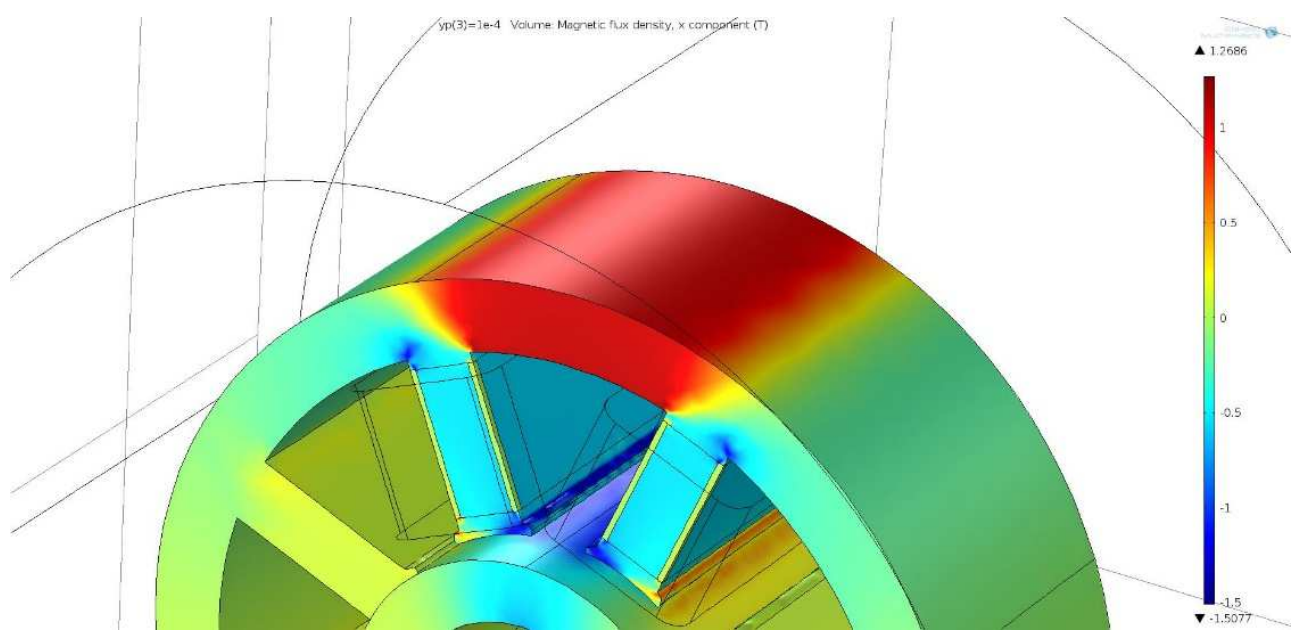

Fig. 3. Magnetic flux density: a) nominal position of the shaft; b) the $0,1 \mathrm{~mm}$ displacement of the shaft 
a)

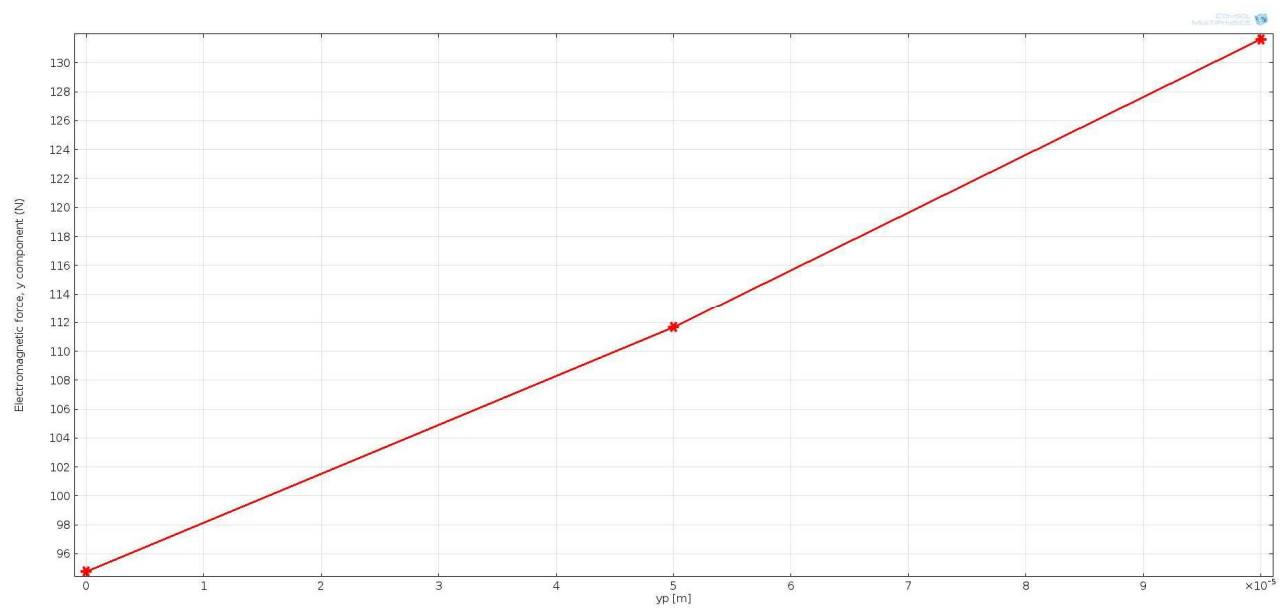

b)

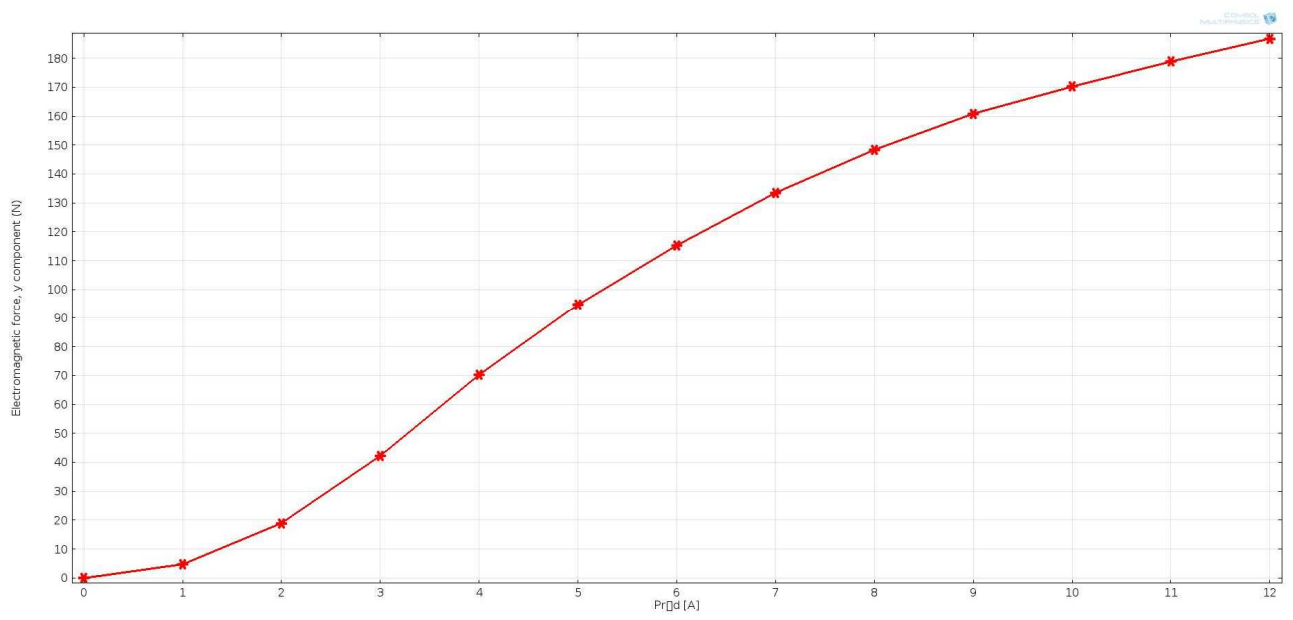

Fig. 4. The diagram of electromagnetic force: a) for the differ value of air gap; b) for the change of the operation current values

\section{Laboratory analysis}

The described active magnetic bearing system is elaborated and investigated in Jet Engine Laboratory. The laboratory stand is presented in Figure 1. While, in Figure 5 is shown the AMB laboratory model.

The experimental tests are consisted of the parameters measurement of the stator electrical windings. The RLC bridge is used during the tests. The measurements allow to verify the designed and made of active magnetic bearing components. The knowledge of these parameters is important for the selection of the power system parameters and to determine the controller parameters. These results are implemented in mathematical and simulation engine models. There are implemented in Comsol Multiphysics and Matlab software. 
During the laboratory tests are measured the static characteristics of the magnetic bearings with various shaft position in stator (Figure 6 and 7), too. The position of rotor changes the air gap in magnetic bearing. During the tests, the work point is changed from $-0.4 \mathrm{~mm}$ to +4 $\mathrm{mm}$. The air gap is changed from $0.2 \mathrm{~mm}$ to $0[\mathrm{~mm}]$ with the rotor moving in the vertical direction (blue characteristic) and from 0 to $0.2[\mathrm{~mm}]$ (red characteristic). The move is relative to nominal position. The position measurements are proceed with use of two dial sensors located to the left and right rotor side.

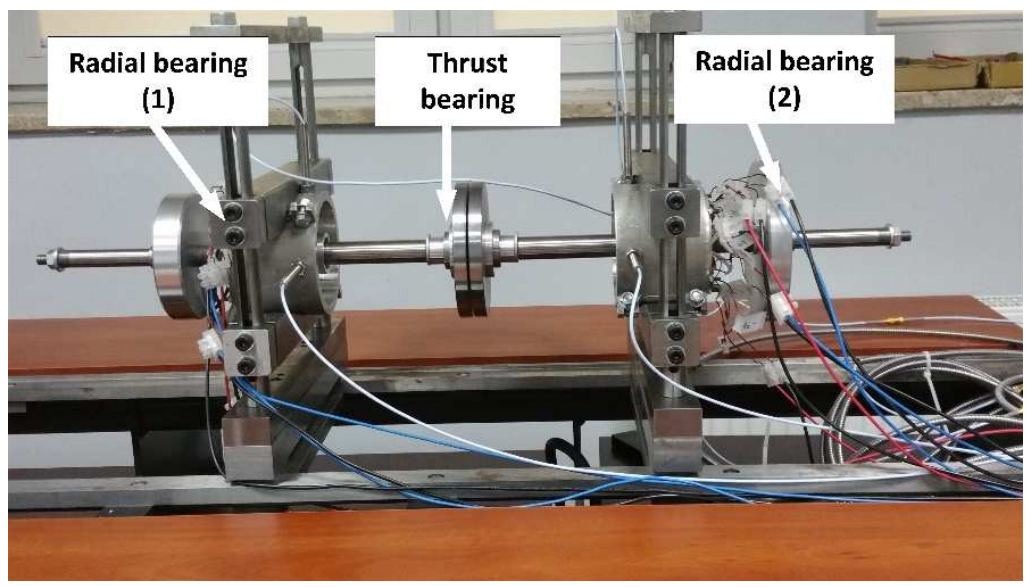

Fig. 5. The laboratory model of active magnetic bearing of jet engine

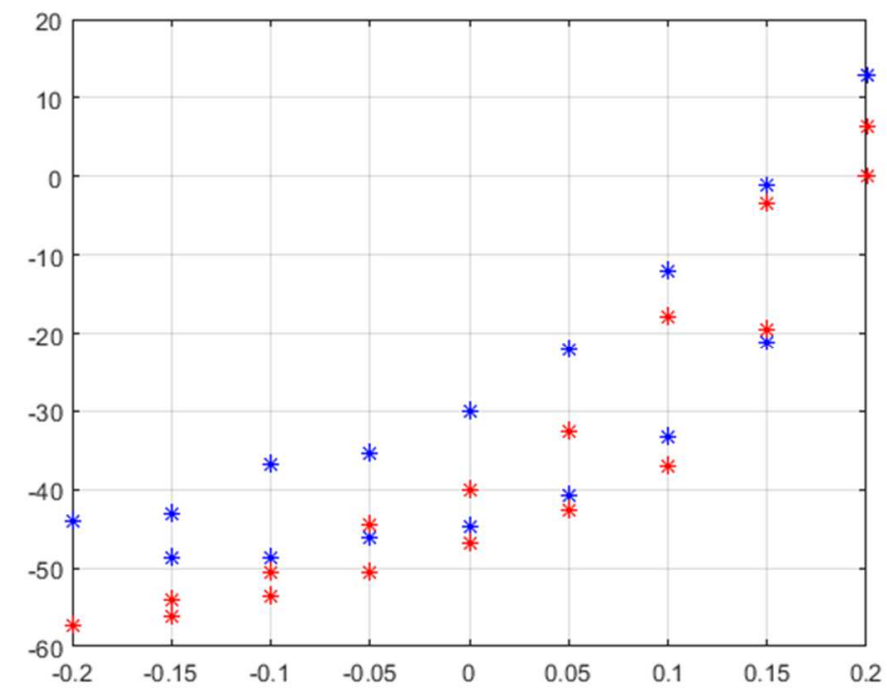

Fig. 6. The measure of air gap changes for the work point $2 \mathrm{~A}$

During next test are measured the rotor attraction force foe differ value of work points. It is changed from 2 to $4 \mathrm{~A}$ with a step $0.2 \mathrm{~A}$. Due to the non-linearity of these characteristics, the parameters are measured two times to determine the characteristic trends. Figure 7 is shown the current values for differ work point. These characteristics have been plotted to show the measurement accuracy for a circuit current in two directions (rotor movement). 

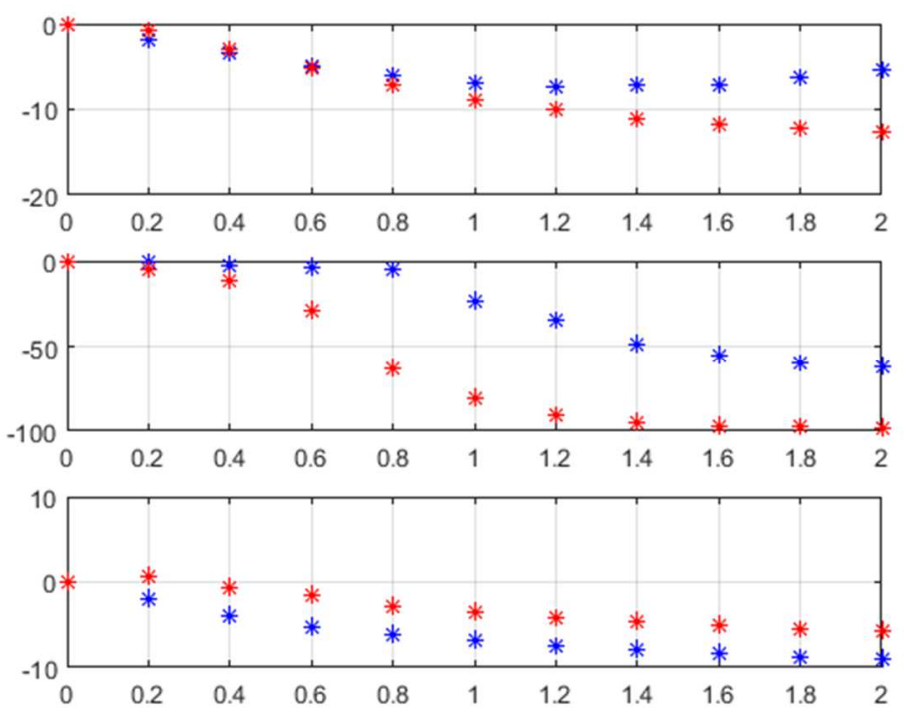

Fig. 7. The force characteristics in function of the work point current

\section{Conclusion}

In the paper are presented results of the simulation and laboratory analyses of the modernized TS-21 jet engine. These analyses are consisted in examining the properties of active magnetic suspension in engine technology. This construction has got a lot of advantages then classical electromechanical bearings. The finite element method is used to verify the construction parameters of designed magnetic bearing system. This method allows estimate parameters of the AMB in aircraft engine.

The active magnetic bearing technology are used in modernized jet engine to improve the environmental operating conditions.

\section{References}

1. Moir I., Seabridge A.: "Aircraft systems - Mechanical, electrical and avionics subsystem integration”, John Wiley \& Sons, pp. 227-238, (2008)

2. Lempke, T.A., Design and analysis of a novel low loss homopolar electrodynamic bearing, Doctoral Thesis, KTH Electrical Engineering, Stockholm., (2005)

3. Falkowski K., Gosiewski Z.: Analytical Method of the Magnetic Forces Estimation in passive Magnetic Bearings, The 8th International Conference on Motion and Vibration Control MOVIC 2006, Korea, September (2006)

4. Falkowski K., Henzel M., Mazurek P., Magnetic suspension system for aircraft engine, 10th International Conference on Mechatronic Systems and Materials „,MSM 2014”, July $7 \div 10$, Opole, Poland, (2014)

5. Henzel M., Mazurek P.: „The analysis of the control system of the active magnetic bearing", Electrodynamic and mechatronic systems, 3rd International Students Conference on Electrodynamics and Mechatronics (SCE III), IEEE, Opole (2011) 
6. Henzel M., Mazurek P. The rapid prototyping of active magnetic bearing, Advances in Intelligent Systems and Computing, Recent Advances in Automation, Robotics and Measuring Techniques, Springer, 267, pp. 155-166, (2014) 